\title{
Molecular detection of exercise-induced free radicals following ascorbate prophylaxis in type 1 diabetes mellitus: a randomised controlled trial
}

\author{
G. W. Davison • T. Ashton • L. George • I. S. Young • \\ J. McEneny • B. Davies • S. K. Jackson • J. R. Peters • \\ D. M. Bailey
}

Received: 29 February 2008 /Accepted: 30 May 2008 / Published online: 4 September 2008

(C) Springer-Verlag 2008

\begin{abstract}
Aims/hypothesis Patients with type 1 diabetes mellitus are more susceptible than healthy individuals to exercise-induced oxidative stress and vascular endothelial dysfunction, which has important implications for the progression of disease. Thus, in the present study, we designed a randomised doubleblind, placebo-controlled trial to test the original hypothesis that oral prophylaxis with vitamin $\mathrm{C}$ attenuates rest and
\end{abstract}

G. W. Davison $(\bowtie)$

Exercise Sciences Research Institute,

University of Ulster at Jordanstown,

Shore Road, Newtownabbey,

County Antrim BT37 OQB, UK

e-mail: gw.davison@ulster.ac.uk

L. George

Diabetes Research Unit, Llandough Hospital,

Cardiff, UK

\section{S. Young $\cdot$ J. McEneny}

Nutrition and Metabolism Research Group,

Wellcome Research Laboratories,

Belfast, UK

T. Ashton $\cdot$ B. Davies $\cdot$ D. M. Bailey

Faculty of Health, Science and Sport, University of Glamorgan,

Pontypridd, UK

\section{S. K. Jackson}

Centre for Research in Biomedicine, Faculty of Applied Sciences, University of the West of England,

Bristol, UK

\section{J. R. Peters}

Department of Medicine, University Hospital of Wales,

Cardiff, UK exercise-induced free radical-mediated lipid peroxidation in type 1 diabetes mellitus.

Methods All data were collected from hospitalised diabetic patients. The electron paramagnetic resonance spectroscopic detection of spin-trapped $\alpha$-phenyl-tert-butylnitrone (PBN) adducts was combined with the use of supporting markers of lipid peroxidation and non-enzymatic antioxidants to assess exercise-induced oxidative stress in male patients with type 1 diabetes $\left(\mathrm{HbA}_{1 \mathrm{c}} 7.9 \pm 1 \%, n=12\right)$ and healthy controls $\left(\mathrm{HbA}_{1 \mathrm{c}} 4.6 \pm 0.5 \%, n=14\right)$. Following participant randomisation using numbers in a sealed envelope, venous blood samples were obtained at rest, after a maximal exercise challenge and before and $2 \mathrm{~h}$ after oral ingestion of $1 \mathrm{~g}$ ascorbate or placebo. Participants and lead investigators were blinded to the administration of either placebo or ascorbate treatments. Primary outcome was the difference in changes in free radicals following ascorbate ingestion.

Results Six diabetic patients and seven healthy control participants were randomised to each of the placebo and ascorbate groups. Diabetic patients $(n=12)$ exhibited an elevated concentration of PBN adducts ( $p<0.05$ vs healthy, $n=14$ ), which were confirmed as secondary, lipid-derived oxygen-centred alkoxyl (RO) radicals $\left(\mathrm{a}_{\text {nitrogen }}=1.37 \mathrm{mT}\right.$ and $\mathrm{a} \beta_{\text {hydrogen }}=0.18 \mathrm{mT}$ ). Lipid hydroperoxides were also selectively elevated and associated with a depression of retinol and lycopene $(p<0.05$ vs healthy). Vitamin C supplementation increased plasma vitamin $\mathrm{C}$ concentration to a similar degree in both groups $(p<0.05$ vs presupplementation) and attenuated the exercise-induced oxidative stress response ( $p<0.05$ vs healthy).

There were no selective treatment differences between groups in the primary outcome variable.

Conclusions/interpretation These findings are the first to suggest that oral vitamin $\mathrm{C}$ supplementation provides an 
effective prophylaxis against exercise-induced free radicalmediated lipid peroxidation in human diabetic blood.

\section{Clinical trials registration number: ISRCTN96164937}

Funding: No external funding.

Keywords Ascorbic acid - Electron paramagnetic resonance $\cdot$ Free radicals $\cdot$ Glucose $\cdot$ Type 1 diabetes mellitus

$\begin{array}{ll}\text { Abbreviations } \\ \text { EPR } & \text { electron paramagnetic resonance } \\ \mathrm{HCC} & \text { hyperfine coupling constant } \\ \mathrm{LOOH} & \text { lipid hydroperoxides } \\ \mathrm{PBN} & \alpha \text {-phenyl-tert-butylnitrone } \\ \mathrm{RO} & \text { alkoxyl } \\ \mathrm{ROS} & \text { reactive oxygen species } \\ \dot{V} \mathrm{O}_{2} & \text { oxygen uptake } \\ \dot{V} \mathrm{O}_{2 \text { peak }} & \text { maximal oxygen uptake }\end{array}$

\section{Introduction}

Diabetes mellitus is a chronic disease characterised by the relative or absolute deficiency of insulin and hyperglycaemia. Reports suggest that patients with diabetes mellitus are susceptible to increased levels of oxidative stress [1, 2], although it is not known whether the increase in reactive oxygen species (ROS) is a causative factor or merely an epiphenomenon. Poor intravascular substrate control is largely regarded as a factor contributing to the increase in superoxide anions $\left(\mathrm{O}_{2}{ }^{-}{ }^{-}\right)$that has previously been observed in diabetic serum [3]. Other potential mechanisms relating to enhanced oxidative stress in diabetes include a compromised antioxidant defence system, glucose autoxidation, the formation of advanced glycated end-products and a change in the glutathione redox status [4]. Strenuous exercise has also been shown to be an independent cause of oxidative stress and indeed increased resting and exercise-induced oxidative stress was recently confirmed in male type 1 diabetic patients by our group, when electron paramagnetic resonance (EPR) spectroscopy was combined with an ex vivo spin-trapping technique using $\alpha$-phenyl-tert-butylnitrone (PBN). Compared with healthy controls, patients with type 1 diabetes presented with an increase in the serum concentration of PBN adducts both at rest and following exhaustive exercise [1]. These data were complemented by a selective increase in supporting biomarkers of lipid peroxidation and functional decreases in non-enzymatic antioxidants.

Although a negative role of free radicals in many disease states is supported by much evidence, there have been promising suggestions for therapeutic antioxidant approaches
[5]. While cells within the body are endowed with a rich enzymatic antioxidant defence system (i.e. superoxide dismutase and $\mathrm{H}_{2} \mathrm{O}_{2}$-removing enzymes), this system is believed to be inadequate to prevent oxidative damage; thus, exogenous antioxidants may be important in maintaining health [6].

Ascorbic acid is an essential antioxidant in humans, and in subclinical ascorbic acid deficiency oxidative stress is evident in nearly all tissues despite sufficient concentrations of other antioxidants, including $\alpha$-tocopherol, glutathione, catalase and superoxide dismutase [7]. It is highly versatile, capable of reacting with many aqueous ROS, and forms the first line of antioxidant defence in human plasma exposed to a variety of oxidant insults [8]. However, the benefits of ascorbic acid prophylaxis remain equivocal, with human studies demonstrating an improvement [9], no change [10], or an increase in ROS and subsequent deterioration in vascular function $[11,12]$. Concerns have been raised about the administration of ascorbic acid in the presence of redoxactive transition metal ions, since ascorbate can reduce transition metal ions and catalyse the Fenton-driven generation of hydroxyl and alkoxyl radicals in vitro [13]. Although the thermodynamics of this reaction in vivo remain controversial [14], an acute bout of physical exercise has been shown to liberate extracellular 'catalytic' iron [15] that, in the presence of supplementary ascorbic acid, may potentially compound the generation of ROS [16].

To the best of our knowledge, no study to date has examined the metabolic implications of ascorbic acid supplementation for exercise-induced oxidative stress in the setting of type 1 diabetes. Consistent with the human literature [1], we hypothesised that, compared with healthy controls, (a) in type 1 diabetic patients exercise would compound basal oxidative stress, and (b) ascorbic acid would provide effective prophylaxis. We used a randomised, double-blind, placebo-controlled experimental design incorporating an EPR spin-trapping technique combined with a comprehensive assessment of lipid peroxidation and non-enzymatic antioxidants to test these hypotheses.

\section{Methods}

Participant characteristics and ethical approval

Twelve male type 1 diabetic patients and 14 apparently healthy male volunteers were recruited for the present study (see Table 1 for participant characteristics). Diabetic volunteers were recruited from the adult diabetic clinic at the University Hospital of Wales using the following inclusion criteria: (1) male, aged 18-30 years; (2) $\mathrm{HbA}_{1 \mathrm{c}}$ between 7\% and $10 \%$; (3) negative for microalbuminuria; and (4) no underlying vascular complications. Non-diabetic control 
Table 1 Age and physiological characteristics of participants

\begin{tabular}{|c|c|c|c|c|}
\hline \multirow[t]{2}{*}{ Variable } & \multicolumn{2}{|c|}{ Diabetic patients $(n=12)$} & \multicolumn{2}{|c|}{ Healthy participants $(n=14)$} \\
\hline & Vitamin $C(n=6)$ & Placebo $(n=6)$ & Vitamin C $(n=7)$ & Placebo $(n=7)$ \\
\hline Age (years) & $27 \pm 2$ & $27.5 \pm 5$ & $24 \pm 1$ & $24 \pm 3$ \\
\hline Stature $(\mathrm{m})$ & $1.78 \pm 8$ & $1.87 \pm 8$ & $1.78 \pm 7$ & $1.75 \pm 4$ \\
\hline Body mass $(\mathrm{kg})$ : main effect for group & $82 \pm 15$ & $94 \pm 19$ & $77 \pm 7$ & $74 \pm 11$ \\
\hline Body mass index $\left(\mathrm{kg} / \mathrm{m}^{2}\right)$ & $25 \pm 3$ & $27 \pm 6$ & $24 \pm 2$ & $24 \pm 3$ \\
\hline Duration of diabetes (years) & $14 \pm 9$ & $8 \pm 7$ & - & - \\
\hline Daily insulin dose (U/day) & $88 \pm 33$ & $64 \pm 45$ & - & - \\
\hline
\end{tabular}

All values are mean \pm SD. Main effect for group indicates a difference $(p<0.05)$ between diabetic and healthy participants (pooled vitamin $\mathrm{C}$ and placebo values)

participants were recruited from the student population of the University of Glamorgan using the following inclusion criteria: (1) matched for age; (2) no metabolic or circulatory medical condition; and (3) no family history of diabetes, confirmed by interview and medical history questionnaire. All participants were non-smokers and abstained from dietary antioxidant supplementation. The Bro Taf Research Ethics Committee granted ethical approval and written informed consent was obtained from each volunteer prior to participation. All procedures were conducted in accordance with the Declaration of Helsinki.

\section{Experimental design}

The present study constituted a balanced, randomised, double-blind, placebo-controlled trial.

\section{Procedure}

On arrival of participants at the laboratory, their body mass and stature were measured according to standard methods. Each participant was subsequently required to ingest ascorbic acid or a placebo (see below for information) prior to cycling to volitional exhaustion on a friction-braked cycle ergometer (Monark 824ع; Monark, Stockholm, Sweden). The test was designed to be progressive and incremental in order to elicit peak maximal oxygen uptake $\left(\dot{V} \mathrm{O}_{2 \text { peak }}\right)$. A cadence of $60 \mathrm{rpm}$ was maintained while workload was increased by $0.5 \mathrm{~kg}$ every $3 \mathrm{~min}$ until volitional fatigue. Oxygen uptake $\left(\dot{V} \mathrm{O}_{2}\right)$ was monitored during exercise using an on-line automated gas analysis system (CPX/D; Medgraphics, Manchester, UK). Heart rate was recorded using a short angle telemetry system (Polar S610 Sport tester; Polar Electro, Kempele, Finland). Participants were instructed to refrain from exercise and alcohol for $24 \mathrm{~h}$ before the test and to maintain their usual dietary pattern. Dietary composition and energy intake in the $72 \mathrm{~h}$ before the exercise test was recorded by means of a dietary record and assessed using a commercially available nutritional assessment package (Nutri-check, Health Options, Cirencester, UK). To ensure standardisation of dietary records, a registered nutritionist advised on how to fill out the diet records. Diabetic participants were instructed to refrain from their morning insulin dose. All exercise tests were performed between 09:00 and 10:00 hours on the ward of the diabetic unit with a physician present.

\section{Supplementation}

Twelve diabetic patients and 14 healthy control participants received an acute oral bolus dose of either $1 \mathrm{~g}(2 \times 500 \mathrm{mg})$ of ascorbic acid (batch SCP g1514; Nova Laboratories, Wigston, UK) or placebo (batch SCP g1515; Nova Laboratories), $2 \mathrm{~h}$ prior to the exercise challenge in a balanced fashion. The period of $2 \mathrm{~h}$ was chosen specifically to allow the venous concentration of ascorbate to rise from baseline to $>100 \mu \mathrm{mol} / 1$ to near cell saturation, based on previous work by Ashton et al. [9]. The participants were given a small volume of water in order to ensure complete ingestion. All participants consumed the two tablets, which were administered under supervision.

\section{Haematology}

Sampling Venous blood was collected following a $12 \mathrm{~h}$ overnight fast from an antecubital forearm vein following 20 min supine rest and immediately after exercise using the Vacutainer method (Becton-Dickinson, Oxford, UK). Blood samples for lipid soluble antioxidants, ascorbic acid and $\mathrm{HbA}_{1 \mathrm{c}}$ were collected in anaerobic glass vacutainers containing EDTA and immediately placed on ice, while samples for EPR and lipid hydroperoxide (LOOH) determinations were collected in serum separation glass Vacutainer tubes and allowed to clot for $10 \mathrm{~min}$ in the dark. Blood for glucose determination was collected in sodium fluoride EDTA tubes. After centrifugation at 3,000 rpm at $4^{\circ} \mathrm{C}$ for $10 \mathrm{~min}$, the serum/plasma samples were stored at 
$-80^{\circ} \mathrm{C}$. Blood samples for EPR, glucose and $\mathrm{HbA}_{1 \mathrm{c}}$ determination were assayed on the same experimental day; the remaining samples were assayed within 6 weeks of collection. All samples from the same participant were analysed within the same batch.

\section{Analyses}

Lipid peroxidation Susceptibility to exercise-induced lipid peroxidation was measured using the ferrous iron/xylenol orange assay [17]. This method quantifies the susceptibility to iron-induced LOOH formation in blood. Intra- and interassay CVs at $0.57 \mu \mathrm{mol} / 1$ were $4.6 \%$ and $6 \%$ respectively.

Lipid soluble and aqueous antioxidants Endogenous lipidsoluble antioxidant activities, including plasma $\alpha$-tocopherol, retinol, lycopene and $\alpha$ - and $\beta$-carotene, were estimated using the simultaneous HPLC assay of Thurnham et al. [18] and Catignani and Bieri [19]. Intra- and inter-assay CVs were both $<5 \%$. The fluorometric assay of Vuilleumier and Keck [20] was used to determine plasma ascorbic acid concentration. The inter-assay $\mathrm{CV}$ at a concentration of $51.11 \mu \mathrm{mol} / \mathrm{l}$ was $0.72 \%$.

Blood glucose and $\mathrm{HbA}_{1 c}$ Blood glucose was measured by dry chemistry slide technology on an Vitros 950 analyser (Ortho Clinical Diagnostics, Raritan, NJ, USA). The intraassay $\mathrm{CV}$ at a glucose concentration of $6.1 \mathrm{mmol} / \mathrm{l}$ was $2.0 \%$ and that at $14.7 \mathrm{mmol} / \mathrm{l}$ was $1.12 \%$. The HPLC method of Philcox et al. [21] was used to determine $\mathrm{HbA}_{1 \mathrm{c}}$ percentage.

$P B N$ adduct extraction and EPR analysis EPR spectroscopy in conjunction with ex vivo spin trapping using PBN was used to investigate the formation of free radical species, and the method used was identical to that of Davison et al. [1]. Nuclear hyperfine coupling constants (HCCs) were confirmed following computer simulation using SimEPR32 software [22]. The relative concentrations of PBN adducts (expressed in arbitrary units), as opposed to absolute concentrations according to a calibration curve, were determined by measuring the mean signal intensity of each spectral peak-to-trough line height. The intra-assay $\mathrm{CV}$ at 1,795 arbitrary units was $5.2 \%$ [2].

Packed cell volume and haemoglobin Resting and postexercise packed cell volumes and $\mathrm{Hb}$ concentrations were measured in whole blood to correct for acute-exercise induced plasma volume shifts using the equations of Dill and Costill [23]. Packed cell volume (\%) was measured using the microcapillary reader technique, and corrected by $1.5 \%$ for plasma trapped within erythrocytes [24]. Haemo- globin $(\mathrm{g} / \mathrm{dl})$ was measured using a $\beta$-haemoglobin photometer (Hemocue, Angelholm, Sweden).

\section{Statistical analysis}

Statistical analysis was performed using the SPSS statistics package (version 11.0; SPSS, Woking, UK). A prospective calculation of power was performed using the equations of Altman [25], while retrospective power was determined using SPSS. Data were analysed using parametric statistics following mathematical confirmation of a normal distribution using repeated Shapiro-Wilk $W$ tests. Baseline data were compared using a two-way ANOVA. Exerciseinduced changes in selected dependent variables were analysed using a three-way repeated measures ANOVA that incorporated one within-participant factor (state, rest vs exercise) and two between-participant factors (group, diabetic vs healthy; treatment, ascorbic acid vs placebo). When a significant interaction effect was detected, within-participant factors were analysed using Bonferroni-corrected paired samples $t$ tests. Between-participant differences were analysed using a one-way ANOVA with the a posteriori Tukey honestly significant difference test. Relationships between selected dependent variables were examined using the Pearson product moment correlation. The alpha level was established at $p<0.05$ and all values are reported as mean $\pm \mathrm{SD}$.

\section{Results}

Energy intake and composition

There were no significant differences in energy intake and micronutrient composition between groups (Table 2), and all values were within the recommended UK daily range [26].

\section{Exercise performance}

Healthy participants achieved a higher maximal oxygen consumption and power output relative to the diabetic group, due to a selective difference in both diabetic treatment groups ( $p<0.05$ vs healthy group; Table 3 ). Ascorbic acid supplementation did not influence any cardiopulmonary variable.

Free radical-mediated oxidative stress

The HCCs for all PBN adducts were (nitrogen) $\mathrm{a}_{\mathrm{N}}=$ $1.37 \mathrm{mT}$ and (hydrogen) $\mathrm{a} \beta_{\mathrm{H}}=0.18 \mathrm{mT}$, as confirmed by computer simulation (Fig. 1), and are consistent with the trapping of a secondary oxygen-centred lipid-derived 
Table 2 Nutritional profile for diabetic and healthy groups

\begin{tabular}{|c|c|c|c|c|}
\hline \multirow[t]{2}{*}{ Variable } & \multicolumn{2}{|c|}{ Diabetic patients $(n=12)$} & \multicolumn{2}{|c|}{ Healthy participants $(n=14)$} \\
\hline & Vitamin C $(n=6)$ & Placebo $(n=6)$ & Vitamin C $(n=7)$ & Placebo $(n=7)$ \\
\hline Energy (kcal/day) & $2,747 \pm 597$ & $2,478 \pm 453$ & $2,861 \pm 622$ & $3,048 \pm 868$ \\
\hline Fat (g/day) & $87 \pm 42$ & $61 \pm 42$ & $145 \pm 63$ & $116 \pm 51$ \\
\hline Carbohydrate (g/day) & $372 \pm 101$ & $355 \pm 127$ & $358 \pm 94$ & $411 \pm 129$ \\
\hline Protein (g/day) & $84 \pm 32$ & $79 \pm 23$ & $67 \pm 32$ & $82.8 \pm 34$ \\
\hline Sugar (g/day) & $173 \pm 97$ & $178 \pm 82$ & $195 \pm 98$ & $181 \pm 101$ \\
\hline PUFA (g/day) & $24 \pm 11$ & $21 \pm 9$ & $28 \pm 10$ & $20 \pm 7$ \\
\hline Saturated fat (g/day) & $49 \pm 18$ & $44 \pm 16$ & $52 \pm 19$ & $47 \pm 16$ \\
\hline Fibre (g/day) & $14 \pm 6$ & $11 \pm 5$ & $16 \pm 8$ & $18 \pm 8$ \\
\hline
\end{tabular}

Values are mean \pm SD

PUFA, polyunsaturated fatty acids

alkoxyl free radical species. Free radical and LOOH concentrations were greater in the diabetic than in the healthy group (diabetic vs healthy, $p<0.05$ ) (Table 4). Ascorbic acid supplementation attenuated the free radical and $\mathrm{LOOH}$ concentrations (ascorbic acid vs placebo, $p<0.05$ ), but these changes were not selectively different between groups (diabetic vs healthy, $p>0.05$ ). Ascorbic acid supplementation also decreased the amount of free radicals produced during exhaustive exercise (state $\times$ treatment, $p<0.05$ ). Typical EPR spectra showing the effects of ascorbic acid on rest and exercise PBN adduct concentration are displayed in Figs 2 and 3.

Table 4 shows the effect of ascorbic acid supplementation on rest and exercise free radical concentration for the diabetic and healthy groups. Free radical concentration was lower following vitamin $\mathrm{C}$ supplementation, with no change as a result of physical exercise, i.e. vitamin $\mathrm{C}$ supplementation decreased resting oxidative stress (main effect for state: pooled data, pre-supplementation vs post- supplementation [rest] vs post-supplementation [exercise] $p<0.05$, Table 4). There was an interaction effect for state $\times$ treatment $(p<0.05)$ and state $\times$ group $(p<0.05)$, although no post hoc differences were detected for the latter interaction. No three-way interaction effect was observed (state $\times$ group $\times$ treatment, $p>0.05$; retrospective power calculation, 0.495).

\section{Antioxidants}

The main finding (Table 4) was a comparatively greater venous concentration of ascorbic acid in the ascorbic acid group (pooled diabetic and healthy values, $p<0.05$ vs placebo), due to a selective increase in concentration following ascorbic acid supplementation (pre-supplementation vs post-supplementation [rest] $p<0.05$ ). $\alpha$-Tocopherol was lower in the healthy group than in the diabetic group (pooled ascorbic acid and placebo, $p<0.05$ vs diabetic). In contrast, plasma lycopene and retinol were comparatively

Table 3 Maximal exercise data for diabetic and healthy groups

\begin{tabular}{|c|c|c|c|c|}
\hline \multirow[t]{2}{*}{ Variable } & \multicolumn{2}{|c|}{ Diabetic patients $(n=12)$} & \multicolumn{2}{|c|}{ Healthy participants $(n=14)$} \\
\hline & $\begin{array}{l}\text { Vitamin C } \\
(n=6)\end{array}$ & $\begin{array}{l}\text { Placebo } \\
(n=6)\end{array}$ & $\begin{array}{l}\text { Vitamin C } \\
(n=7)\end{array}$ & $\begin{array}{l}\text { Placebo } \\
(n=7)\end{array}$ \\
\hline $\begin{array}{l}\dot{V} \mathrm{O}_{2 \text { peak }}\left(\mathrm{ml} \mathrm{kg}^{-1} \mathrm{~min}^{-1}\right): \text { main effect for group; } \\
\text { interaction effect for group } \times \text { treatment }\end{array}$ & $36 \pm 5.8^{\mathrm{a}}$ & $36 \pm 3.7^{\mathrm{a}}$ & $56 \pm 10.3$ & $52 \pm 4.5$ \\
\hline RER (arbitrary units) & $1.19 \pm 0.02$ & $1.23 \pm 0.1$ & $1.16 \pm 0.03$ & $1.22 \pm 0.09$ \\
\hline Heart rate (beats per min) & $186 \pm 6$ & $187 \pm 8$ & $192 \pm 5$ & $180 \pm 15$ \\
\hline RPE (arbitrary units) & $18 \pm 1$ & $17 \pm 1$ & $18 \pm 2$ & $18 \pm 1$ \\
\hline Power output (W): main effect for group & $222 \pm 24$ & $222 \pm 24$ & $258 \pm 54$ & $246 \pm 42$ \\
\hline $\begin{array}{l}\text { Exercise time }(\mathrm{min}) \text { : interaction effect } \\
\text { for group } \times \text { treatment }\end{array}$ & $12.08 \pm 3.26$ & $14.18 \pm 2.8$ & $17.44 \pm 5$ & $15.54 \pm 3.2$ \\
\hline
\end{tabular}

Values are mean $\pm \mathrm{SD}$

${ }^{\mathrm{a}}$ Difference between groups as a function of treatment $(p<0.05)$

RER, maximal respiratory exchange ratio; RPE, rate of perceived exertion 


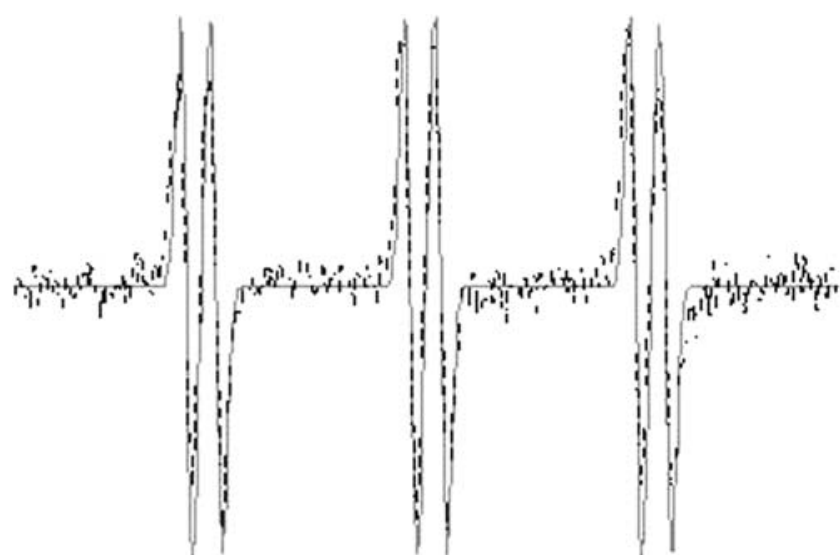

Fig. 1 Computer simulation identified a single species with nuclear hyperfine splittings of $\mathrm{a}_{\mathrm{N}}=1.37 \mathrm{mT}$ and $\mathrm{a} \beta_{\mathrm{H}}=0.18 \mathrm{mT}$. Solid line, simulation; dashed line, experiment

lower in the diabetic group (pooled ascorbic acid and placebo, $p<0.05$ vs healthy). There was a state $\times$ group interaction for $\beta$-carotene $(p<0.05)$; however, the post hoc test showed no significant changes $(p>0.05)$.

\section{Glucose metabolism}

$\mathrm{HbA}_{1 \mathrm{c}}$ was higher in both diabetic groups than in the healthy groups (diabetic vs healthy as a function of treatment, $p<0.05$; values for diabetic placebo and ascorbic acid and control placebo and ascorbic acid were $8.8 \pm 1.1$, $7.5 \pm 1.2,4.5 \pm 0.5$ and $4.8 \pm 0.6 \%$ respectively). Furthermore, the diabetic group had a higher blood glucose concentration than the healthy group (pooled ascorbic acid and placebo values, $p<0.05$ vs healthy); however, no interaction effect was observed (Table 4).

\section{Experimental inter-assay correlations}

Correlations are expressed as $\Delta=$ pre-exercise-post-exercise. There were positive correlations between $\triangle \mathrm{PBN}$ adduct and $\Delta \mathrm{LOOH}$ in the diabetic placebo group $(r=0.99, p<0.05)$ and in the healthy placebo group $(r=0.93, p<0.05)$.

\section{Discussion}

Work from our laboratory has previously shown that patients with type 1 diabetes are susceptible to increased blood levels of free radicals as documented by EPR spectroscopy, the most direct method of measuring free radical species [27]. The present study has consistently confirmed this observation and in addition demonstrates that ascorbate prophylaxis attenuates exercise-induced oxidative stress. However, contrary to our original hypothesis, we did not observe a more marked antioxidant effect in the diabetic patients.
Free radical-mediated lipid peroxidation

All primary HCCs measured were $\mathrm{a}_{\mathrm{N}}=1.37 \mathrm{mT}$ and $\mathrm{a} \beta_{\mathrm{H}}=$ $0.18 \mathrm{mT}$, and are suggestive of secondary oxygen-centred lipid-derived alkoxyl free radicals. Other studies report HCCs similar to those observed in the present study. For example, Anderson et al. [28] measured the PBN adducts of radicals produced in the serum of patients with type 2 diabetes, and attributed the HCC $\left(a_{N}=1.39 \mathrm{mT}\right.$ and $\mathrm{a} \beta_{\mathrm{H}}=$ $0.22 \mathrm{mT}$ ) to alkoxyl free radicals derived from the peroxidation of lipid membranes. Garlick et al. [29] observed values of $\mathrm{a}_{\mathrm{N}}=1.36 \mathrm{mT}$ and $\mathrm{a} \beta_{\mathrm{H}}=0.15 \mathrm{mT}$ in rodent blood and suggested the species were alkoxyl radicals formed as a result of lipid degradation. These findings are supported by the work of Davison et al. [1], who detected lipid free radicals $\left(a_{\mathrm{N}}=1.36 \mathrm{mT}\right.$ and $\left.\mathrm{a} \beta_{\mathrm{H}}=0.17 \mathrm{mT}\right)$ in the blood of type 1 diabetic patients following exercise. Furthermore, EPR spectra from the autoxidation of a variety of polyunsaturated fatty acids showed HCCs $\left(a_{\mathrm{N}}=1.36 \mathrm{mT}\right.$ and $\mathrm{a} \beta_{\mathrm{H}}=$ $0.18 \mathrm{mT}$ ) identical to those of human blood in the present study, which supports our observation that the free radical species detected were lipid in origin [30].

In addition to a greater concentration of free radical species, the diabetic group had a greater concentration of circulating $\mathrm{LOOH}$. This, in combination with the positive association between $\Delta \mathrm{PBN}$-adduct and $\Delta \mathrm{LOOH}$, strongly suggests that the free radicals detected in the present investigation were lipid-derived. This is in agreement with the work of Ashton et al. [31], who also observed a positive correlation between LOOH and PBN adduct concentration at rest $(r=0.80, p<0.05)$ and immediately following exercise using an exercise paradigm identical to that employed in the present study $(r=0.71$, $p<0.05)$. We suggest that the metal-catalysed reductive decomposition of $\mathrm{LOOH}$ may be the precursor of the compound formation of EPR-detectable spin-trapped lipidderived alkoxyl radicals ( $\left.\mathrm{LOOH} \pm \mathrm{Fe}^{2+}=\mathrm{RO} \cdot\right)$. Though clearly downstream of the primary locus of generation, these lipid species are thermodynamically capable of initiating and propagating further oxidative damage to important biomolecules [32].

Since lipid radicals are known to originate from phospholipid membranes [33], it is postulated that the diabetic group experienced greater primary free radical attack to erythrocyte membranes or circulating lipids, yielding a greater concentration of free radical intermediates [34], which were then detected by EPR spectroscopy. Based upon evidence provided by Gillery et al. [35], it is possible that the main initiating oxidising agent is $\mathrm{O}_{2}{ }^{-}$formed as a result of glucose modification. Hunt et al. [36] observed an increase in hydroxyl radicals when hydroxylate benzoic acid was incubated with hyperglycaemic levels of glucose in vitro. In providing support for possible increased rates of glucose 
Table 4 Lipid oxidation, antioxidant indices and glucose at rest and exercise in diabetic and healthy groups

\begin{tabular}{|c|c|c|c|c|}
\hline \multirow[t]{2}{*}{ Variable } & \multicolumn{2}{|c|}{ Diabetic patients $(n=12)$} & \multicolumn{2}{|c|}{ Healthy participants $(n=14)$} \\
\hline & $\begin{array}{l}\text { Placebo } \\
(n=6)\end{array}$ & $\begin{array}{l}\text { Vitamin C } \\
(n=6)\end{array}$ & $\begin{array}{l}\text { Placebo } \\
(n=7)\end{array}$ & $\begin{array}{l}\text { Vitamin C } \\
(n=7)\end{array}$ \\
\hline \multicolumn{5}{|l|}{ PBN adducts } \\
\hline Pre-supplementation (rest) & $3,540 \pm 2,327$ & $2,769 \pm 1,354$ & $1,758 \pm 688$ & $1,863 \pm 782$ \\
\hline Post-supplementation (rest) & $2,806 \pm 1,657$ & $1,236 \pm 569$ & $1,762 \pm 561$ & $741 \pm 201$ \\
\hline $\begin{array}{l}\text { Post-supplementation (exercise): } \\
\text { main effects for state/treatment/group; } \\
\text { interaction effect for state } \times \text { treatment }\end{array}$ & $3,616 \pm 1,646$ & $1,044 \pm 490$ & $3,875 \pm 1,433$ & $610 \pm 228$ \\
\hline \multicolumn{5}{|l|}{$\mathrm{LOOH}$} \\
\hline Pre-supplementation (rest) & $0.79 \pm 0.16$ & $0.69 \pm 0.27$ & $0.69 \pm 0.1$ & $0.63 \pm 0.11$ \\
\hline Post-supplementation (rest) & $0.85 \pm 0.18$ & $0.69 \pm 0.12$ & $0.70 \pm 0.16$ & $0.64 \pm 0.08$ \\
\hline $\begin{array}{l}\text { Post-supplementation (exercise): } \\
\text { main effects for group/treatment }\end{array}$ & $0.97 \pm 0.13$ & $0.67 \pm 0.19$ & $0.80 \pm 0.18$ & $0.54 \pm 0.08$ \\
\hline \multicolumn{5}{|l|}{ Ascorbic acid } \\
\hline Pre-supplementation (rest) & $41.5 \pm 13.2$ & $43.7 \pm 12.2$ & $50.1 \pm 23.5$ & $55.8 \pm 15.1$ \\
\hline Post-supplementation (rest) & $41.7 \pm 16.2$ & $102.1 \pm 23.4$ & $48.6 \pm 18.8$ & $115.6 \pm 15$ \\
\hline $\begin{array}{l}\text { Post-supplementation (exercise): } \\
\text { main effects for state/treatment; } \\
\text { interaction effect for state } \times \text { treatment }\end{array}$ & $45 \pm 23.4$ & $104.3 \pm 25$ & $49.2 \pm 20.9$ & $111.6 \pm 22$ \\
\hline \multicolumn{5}{|l|}{$\alpha$-Tocopherol } \\
\hline Pre-supplementation (rest) & $21.19 \pm 2$ & $26.07 \pm 8$ & $20.47 \pm 3$ & $17.96 \pm 4.1$ \\
\hline Post-supplementation (rest) & $22.5 \pm 2.7$ & $24.05 \pm 7$ & $20.31 \pm 4.4$ & $19.98 \pm 3.5$ \\
\hline $\begin{array}{l}\text { Post-supplementation (exercise): } \\
\text { main effect for group }\end{array}$ & $20.67 \pm 2.8$ & $22.76 \pm 5.2$ & $21.02 \pm 3.9$ & $19.24 \pm 4.1$ \\
\hline \multicolumn{5}{|l|}{ Retinol } \\
\hline Pre-supplementation (rest) & $0.76 \pm 0.06$ & $1.01 \pm 0.27$ & $1.22 \pm 0.25$ & $1.11 \pm 0.43$ \\
\hline Post-supplementation (rest) & $0.83 \pm 0.13$ & $0.96 \pm 0.24$ & $1.19 \pm 0.33$ & $1.19 \pm 0.37$ \\
\hline $\begin{array}{l}\text { Post-supplementation (exercise): } \\
\text { main effect for group }\end{array}$ & $0.82 \pm 0.1$ & $0.90 \pm 0.17$ & $1.23 \pm 0.30$ & $1.23 \pm 0.38$ \\
\hline \multicolumn{5}{|l|}{ Lycopene } \\
\hline Pre-supplementation (rest) & $0.60 \pm 0.4$ & $0.57 \pm 0.2$ & $1.64 \pm 0.8$ & $1.30 \pm 0.8$ \\
\hline Post-supplementation (rest) & $0.95 \pm 0.8$ & $0.65 \pm 0.5$ & $1.76 \pm 0.7$ & $0.77 \pm 0.5$ \\
\hline $\begin{array}{l}\text { Post-supplementation (exercise): } \\
\text { main effect for group }\end{array}$ & $0.65 \pm 0.5$ & $0.57 \pm 0.3$ & $1.25 \pm 0.8$ & $1.18 \pm 1.0$ \\
\hline \multicolumn{5}{|l|}{$\alpha$-Carotene } \\
\hline Pre-supplementation (rest) & $0.12 \pm 0.04$ & $0.05 \pm 0.02$ & $0.07 \pm 0.09$ & $0.10 \pm 0.06$ \\
\hline Post-supplementation (rest) & $0.12 \pm 0.02$ & $0.08 \pm 0.03$ & $0.10 \pm 0.09$ & $0.08 \pm 0.03$ \\
\hline $\begin{array}{l}\text { Post-supplementation (exercise): } \\
\text { interaction effect for state } \times \text { group }\end{array}$ & $0.10 \pm 0.04$ & $0.06 \pm 0.02$ & $0.08 \pm 0.09$ & $0.11 \pm 0.09$ \\
\hline \multicolumn{5}{|l|}{$\beta$-Carotene } \\
\hline Pre-supplementation (rest) & $0.24 \pm 0.05$ & $0.30 \pm 0.08$ & $0.23 \pm 0.1$ & $0.33 \pm 0.1$ \\
\hline Post-supplementation (rest) & $0.32 \pm 0.12$ & $0.42 \pm 0.2$ & $0.27 \pm 0.1$ & $0.23 \pm 0.1$ \\
\hline Post-supplementation (exercise) & $0.24 \pm 0.09$ & $0.30 \pm 0.1$ & $0.22 \pm 0.1$ & $0.34 \pm 0.2$ \\
\hline \multicolumn{5}{|l|}{ Glucose } \\
\hline Pre-supplementation (rest) & $10 \pm 3.6$ & $11.3 \pm 5.3$ & $4.2 \pm 0.2$ & $4.7 \pm 0.7$ \\
\hline Post-supplementation (rest) & $11.5 \pm 4.5$ & $12.6 \pm 4.5$ & $4.3 \pm 0.4$ & $4.2 \pm 0.3$ \\
\hline $\begin{array}{l}\text { Post-supplementation (exercise): } \\
\text { main effect for group }\end{array}$ & $11.2 \pm 4.5$ & $11 \pm 5.3$ & $4.8 \pm 0.8$ & $4.6 \pm 1$ \\
\hline
\end{tabular}

All values are mean \pm SD and are expressed as $\mu \mathrm{mol} / 1$ except $\mathrm{PBN}$ adducts, which are expressed in arbitrary units. Main effect for group indicates a difference between diabetic vs control (pooled ascorbic acid and placebo values) $(p<0.05)$; main effect for time indicates a difference between presupplementation vs post-supplementation (rest) vs post-supplementation (exercise) (pooled ascorbic acid and placebo values); main effect for treatment indicates a difference between ascorbic acid vs placebo (pooled diabetic and control) $(p<0.05)$; interaction effect (group $\times$ treatment) indicates a difference within/between groups $(p<0.05)$; interaction effect (state $\times$ group) indicates a difference in time as a function of group ( $p<0.05)$; interaction effect (state $\times$ treatment) indicates a difference in time as a function of treatment $(p<0.05)$ 
Fig. 2 EPR PBN adduct spectra extracted ex vivo from serum of diabetic participants: implications of ascorbic acid supplementation and exercise.

a Pre-supplementation (rest),

b post-supplementation (rest),

c post-supplementation (exer-

cise). Spectra were filtered and scaled identically

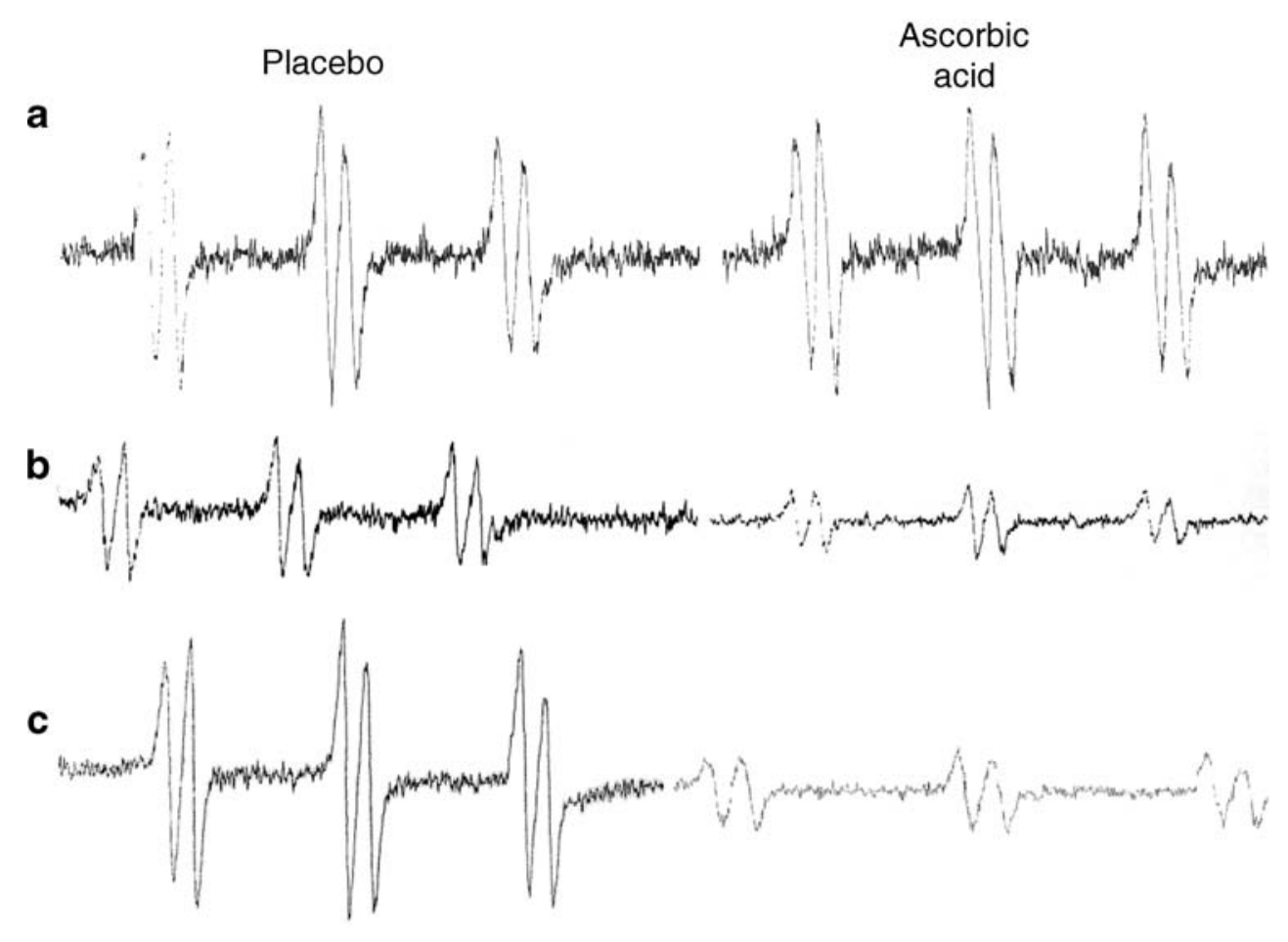

autoxidation and the subsequent generation of free radicals, the diabetic group in this study showed higher blood glucose levels, thus providing more substrate for autoxidation purposes. In addition, it has been suggested that poor metabolic control may influence the generation of $\mathrm{O}_{2}{ }^{-}$ radicals in diabetic serum [3]. This is partially supported our data demonstrating a higher $\mathrm{HbA}_{1 \mathrm{c}}$ level in the diabetic group.
Fig. 3 Typical EPR PBN adduct spectra extracted ex vivo from serum of healthy participants: implications of ascorbic acid supplementation and exercise. a Pre-supplementation (rest), b post-supplementation (rest), c post-supplementation (exercise). Spectra were filtered and scaled identically

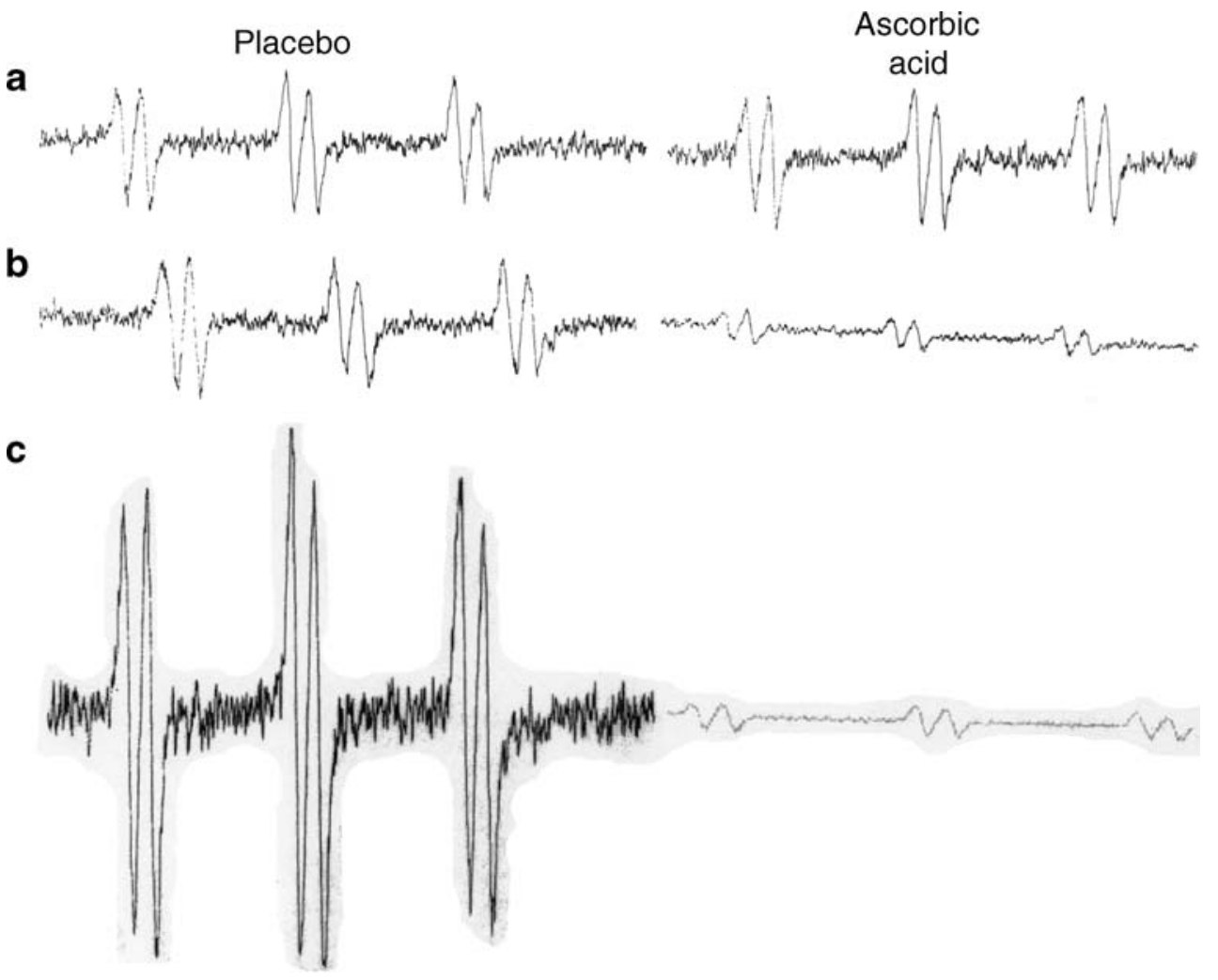


Ascorbate supplementation

Ascorbic acid supplementation lowered the concentrations of both free radicals and $\mathrm{LOOH}$, suggesting that this antioxidant is effective in attenuating lipid peroxidation. There was, however, a mild attenuation of free radical species and $\mathrm{LOOH}$ following ingestion of $1 \mathrm{~g}$ of ascorbic acid, demonstrating that ascorbic acid does not completely abolish PBN adduct production. These findings are in general agreement with the work of Ashton et al. [9] showing a decrease in EPR signal amplitude after supplementation with $1 \mathrm{~g}$ ascorbic acid in ten healthy male volunteers.

We have previously observed an attenuation of EPR signals following the addition of ascorbic acid to the in vitro oxidation of $\alpha$-linolenic acid, postulating that ascorbic acid has the ability to scavenge free radicals generated from a lipid environment [30]. Furthermore, an important control experiment showed that addition of ascorbate to a sample following adduct extraction did not alter EPR signal amplitude, indicating that ascorbate did not simply destroy the trap-radical adduct by reducing the nitroxide to an EPRsilent hydroxylamine. Thus, we are confident that the near ablation of the PBN adduct signal observed following ascorbate prophylaxis can indeed be attributed to its authentic ability to scavenge peroxyl radicals and terminate lipid peroxidation by inhibiting the formation of the alkoxyl radical. We have also shown that not only does ascorbate supplementation decrease PBN adduct concentration, but that it also decreases lipid peroxidation as measured by LOOH [9], providing further support to the concept that ascorbate is acting as a scavenging agent and arresting lipid peroxidation.

Plasma ascorbic acid concentration rose by $61.5 \%$ following ascorbic acid ingestion, agreeing with the work of Thompson et al. [37]. However, what is unknown from the present research is the specific site of free radical scavenging. It is plausible, since plasma is saturated at doses of $1,000 \mathrm{mg}$, that the ascorbic acid scavenged bloodborne free radicals, thus inhibiting the propagation of lipid peroxidation [38]. In support of this idea, Frei et al. [39] have shown that ascorbic acid protects plasma lipids against peroxidative damage induced by aqueous lipid-derived peroxyl radicals and that ascorbic acid is the only plasma antioxidant capable of doing so. Furthermore, Frei et al. [40] suggest that LOOH may be effectively decreased in the plasma by ascorbic acid treatment. Indeed, the decreased $\mathrm{LOOH}$ in the ascorbic acid-supplemented group in the present study would provide support for this claim. It is also feasible that ascorbic acid acted intracellularly as well as in the blood, since cells are saturated at doses of $200 \mathrm{mg}$ [41]. It has been suggested that ascorbic acid is most effective at the aqueous-lipid interface of the cell membrane, scavenging intracellular aqueous radicals [31].
Another potential mechanism of action of ascorbic acid, may involve the regeneration of $\alpha$-tocopherol [42]. As ascorbic acid donates an electron to regenerate the $\alpha$ tocopherol radical back to $\alpha$-tocopherol, ascorbyl radical intermediates may be formed. Because of the location of the unpaired electron on the ascorbyl radical, this radical is relatively unreactive; however, it may interact with other free radical species to either prevent or terminate the process of lipid peroxidation [43]. Evidence suggests that ascorbic acid supplementation can protect against lipid peroxidation in atherogenic lipoproteins in human plasma [44], and Retsky et al. [45] have shown that dehydroascorbic acid, the oxidation product of ascorbic acid, can prevent the initiation of lipid peroxidation in LDL-cholesterol. The decreases in both aqueous-phase lipid-derived radicals and $\mathrm{LOOH}$ demonstrate the effectiveness of ascorbic acid in the present study.

The preferential oxidation of ascorbic acid rather than $\alpha$ tocopherol in terminating the process of lipid peroxidation may be due to the sluggish rate constant reaction of $\alpha$-tocopherol with the lipid (L·) radical. Davies and Timmins [46] showed rate constant reactions of $<10^{5} \mathrm{dm}^{3} \mathrm{~mol}^{-1} \mathrm{~s}^{-1}$ and $1.3 \times$ $10^{7} \mathrm{dm}^{3} \mathrm{~mol}^{-1} \mathrm{~s}^{-1}$ for the interactions of $\alpha$-tocopherol and ascorbic acid respectively with the $\mathrm{L} \cdot$ radical. In addition, Niki et al. [47] suggested that $\alpha$-tocopherol cannot stabilise the alkoxyl radical before attacking polyunsaturated fatty acids, as the reaction rate constant for this interaction is relatively slow.

\section{Antioxidants}

Consistent with previous work from our laboratory, the plasma $\alpha$-tocopherol concentration was found to be higher in diabetic patients than in healthy controls [1], and this may have been due to greater sympathetic activation of lipolysis. However, there was no difference in energy intake between groups and unfortunately fatty acids were not measured; therefore, such an explanation remains speculative.

Another possible reason why the diabetic group was more prone to oxidative stress may be, in part, the decreased circulating concentrations of retinol and lycopene. Crohn's disease patients, in addition to diabetes, show a lower systemic concentration of lycopene in the presence of increased lipid peroxidation [48]. What cannot be determined from the present research, however, is the possibility that both retinol and lycopene may have been consumed as a result of the increased free radical concentration in the diabetic group.

\section{Conclusion}

This study has confirmed that, compared with healthy nondiabetic controls, patients with type 1 diabetes show greater 
oxidative stress. Our findings further suggest that the oral administration of $1 \mathrm{~g}$ ascorbic acid provides effective prophylaxis against vascular free radical generation in both the healthy and diseased state.

Duality of interest The authors declare that there is no duality of interest associated with this manuscript.

\section{References}

1. Davison GW, George L, Jackson SK et al (2002) Exercise, free radicals, and lipid peroxidation in type 1 diabetes mellitus. Free Radic Biol Med 33:1543-1551

2. Laaksonen DE, Uusitupa M, Atalay M, Hanninen O, Niskanen L, Sen CK (1996) Increased resting and exercise-induced oxidative stress in young IDDM men. Diabetes Care 19:569-574

3. Ceriello A, Giugliano D, Quatraro A, Dello Russo P, Lefebvre PJ (1991) Metabolic control may influence the increased superoxide generation in diabetic serum. Diab Med 8:540-542

4. Laaksonen DE, Sen CK (2000) Exercise and oxidative stress in diabetes mellitus. In: Sen CK, Packer L, Hanninen O (eds) Handbook of oxidants and antioxidants in exercise. Elsevier, Amsterdam, pp 1105-1136

5. Halliwell B (1987) Oxidants and human disease: some new concepts. FASEB J 1:358-364

6. Halliwell B (1996) Antioxidants in human health and disease. Annu Rev Nutr 16:33-50

7. Nandi A, Mukhopadhyay CK, Ghosh MK, Chattopadhyay DJ, Chaterjee IB (1997) Evolutionary significance of vitamin C biosynthesis in terrestrial vertebrates. Free Radic Biol Med 22:1047-1054

8. Frei B (1994) Reactive oxygen species and antioxidant vitamins: mechanisms of action. Am J Med 97:3A-5S

9. Ashton T, Young IS, Peters JR et al (1999) Electron spin resonance spectroscopy, exercise, and oxidative stress: an ascorbic acid intervention study. J Appl Physiol 87:2032-2036

10. Wijnen MH, Vader HL, Van Den Wall Bake AW, Roumen RM (2002) Can renal dysfunction after infra-renal aortic aneurysm repair be modified by multi-antioxidant supplementation? J Cardio Surg 43:483-488

11. Galley H, Davies M, Webster N (1996) Ascorbyl radical formation in patients with sepsis: effect of ascorbate loading. Free Radic Biol Med 20:139-143

12. Lachili B, Hininger I, Faure $H$ et al (2001) Increased lipid peroxidation in pregnant women after iron and vitamin $\mathrm{C}$ supplementation. Biol Trace Elem Res 83:103-110

13. Samuni A, Aronovitch J, Godinger D, Chevion M, Czapski G (1983) On the cytotoxicity of vitamin C and metal ions. A sitespecific Fenton mechanism. Eur J Biochem 137:119-124

14. Berger TM, Polidori MC, Dabbagh A et al (1997) Antioxidant activity of vitamin $\mathrm{C}$ in iron-overloaded human plasma. J Biol Chem 272:15656-15660

15. White BC, Krause GS, Aust SD, Eyster GE (1985) Postischemic tissue injury by iron-mediated free radical lipid peroxidation. Ann Emerg Med 14:804-809

16. Bailey DM, Raman S, McEneny J et al (2006) Vitamin C prophylaxis promotes oxidative lipid damage during surgical ischemia-reperfusion. Free Rad Biol Med 40:591-600

17. Wolff SP (1994) Ferrous ion oxidation in presence of ferric ion indicator xylenol orange for measurement of hypoperoxides. Methods Enzymol 233:183-189
18. Thurnham DI, Smith E, Flora PS (1988) Concurrent liquidchromatographic assay of retinol, $\alpha$-tocopherol, $\beta$-carotene, $\alpha$ carotene, lycopene, and $\beta$-cryptoxanthin in plasma with tocopherol acetate as internal standard. Clin Chem 34:377-381

19. Catignani GL, Bieri JG (1983) Simultaneous determination of retinol and $\alpha$-tocopherol in serum or plasma by liquid chromatography. Clin Chem 34:377-381

20. Vuilleumier JP, Keck E (1989) Fluorometric assay of vitamin C in biological materials using a centrifugal analyser with fluorescence attachment. J Micronutrient Anal 5:25-34

21. Philcox JC, Haywood MR, Rofe AM (1992) Hemoglobin A1c by HPLC with the Pharmacia Mono S HR 5/5 cation-exchange column: influence of sample load on optimal chromatographic conditions. Clin Chem 38:1488-1490

22. Adamski A, Spalek T, Sojka (2003) Application of EPR spectroscopy for elucidation of vanadium speciation in $\mathrm{VOx} /$ $\mathrm{ZrO} 2$ catalysts subject to redox treatment. Res Chem Intermed 29:793-804

23. Dill DB, Costill DL (1974) Calculation of the percentage changes in volumes of blood, plasma and red cells in dehydration. J Appl Physiol 37:247-248

24. Dacie JV, Lewis SM (1968) Practical haematology. Churchill, London

25. Altman DG (1980) Statistics and ethics in medical research. How large a sample size? BMJ 281:1336-1338

26. Bender AE, Bender DA (1986) Food tables. Oxford University Press, Oxford

27. Jackson MJ (1999) An overview of the methods for assessment of free radical activity in biology. Proc Nutr Soc 58:10011006

28. Anderson RA, Evans ML, Ellis GR et al (2001) The relationship between post-prandial lipaemia, endothelial function and oxidative stress in healthy individuals and patients with type 2 diabetes. Atherosclerosis 154:475-483

29. Garlick PB, Davies MJ, Herase DJ, Slater TF (1987) Direct detection of free radicals in the reperfused rat heart using electron spin resonance spectroscopy. Circ Res 61:757-760

30. Davison GW, Ashton T, Davies B, Bailey DM (2008) In vitro electron paramagnetic resonance characterization of free radicals: relevance to exercise-induced lipid peroxidation and implications of ascorbate prophylaxis. Free Radic Res 42:379-386

31. Ashton T, Rowlands CC, Jones E et al (1998) Electron spin resonance spectroscopic detection of oxygen-centred radicals in human serum following exhaustive exercise. Eur J Appl Physiol 77:498-502

32. Buettner GR (1993) The pecking order of free radicals and antioxidants: lipid peroxidation, $\alpha$-tocopherol, and ascorbate. Arch Biochem Biophys 300:525-543

33. Duthie GG (1993) Lipid peroxidation. Eur J Clin Nut 47:759-764

34. Clemens MR, Waller HD (1987) Lipid peroxidation in erythrocytes. Chem Phys Lipids 45:251-268

35. Gillery P, Monboisse JC, Maquart FX, Borel JP (1988) Glycation of proteins as a source of superoxide. Diab Metab 14:25-30

36. Hunt JV, Smith CCT, Wolff SP (1990) Autoxidative glycosylation and possible involvement of peroxides and free radicals in LDL modification by glucose. Diabetes 39:1420-1424

37. Thompson D, Williams C, Kingley M et al (2001) Muscle soreness and damage parameters after prolonged intermittent shuttle-running following acute vitamin $\mathrm{C}$ supplementation. Int $\mathrm{J}$ Sports Med 22:68-75

38. Bendich A, Machlin LJ, Scandurra O (1986) The antioxidant role of vitamin C. Free Rad Biol Med 2:419-444

39. Frei B, England E, Ames BN (1989) Ascorbate is an outstanding antioxidant in human plasma. Proc Natl Acad Sci U S A 86:63776381 
40. Frei B, Stocker R, Ames BN (1988) Antioxidant defenses and lipid peroxidation in human blood plasma. Proc Natl Acad Sci U S A 85:9748-9752

41. Levine M, Conry-Cantilena C, Wang Y et al (1996) Vitamin C pharmacokinetics in healthy volunteers: evidence for a recommended dietary allowance. Proc Natl Acad Sci U S A 93:3704-3709

42. Niki E, Saito T, Kawakami A, Kamiya Y (1984) Inhibition of oxidation of methyl linoleate in solution by vitamin $\mathrm{E}$ and vitamin C. J Biol Chem 259:4177-4182

43. Sharma M, Buettner G (1993) Interaction of vitamin C and vitamin E during free radical stress in plasma: an ESR study. Free Radic Biol Med 14:649-653

44. Hyyssonen K, Porkkala E, Salonen R, Korpela H, Salonen JT (1994) Increase in oxidation resistance of atherogenic serum lipoproteins following antioxidant supplementation: a randomized double-blind placebo-controlled clinical trial. Eur J Clin Nutr 48:633-642

45. Retsky KL, Freeman MW, Frei B (1993) Ascorbic acid oxidation product(s) protect human low density lipoprotein against atherogenic modification. J Biol Chem 268:1304-1309

46. Davies MJ, Timmins GS (1996) EPR spectroscopy of biologically relevant free radicals in cellular, ex vivo, and in vivo systems. In: Clark RJH, Hester RE (eds) Biomedical applications of spectroscopy. Wiley, Chichester, pp 217-266

47. Niki E, Noguchi N, Tsuchihashi H, Gotoh N (1995) Interaction among vitamin $\mathrm{C}$, vitamin $\mathrm{E}$, and $\beta$-carotene. Am J Clin Nutr 62:1322S-1326S

48. Wendland BE, Aghdassi E, Tam C et al (2001) Lipid peroxidation and plasma antioxidant micronutrients in Crohn disease. Am J Clin Nutr 74:259-264 